\title{
Name of the Reference Terminology
}

National Cancer Institute

\section{Source}

National Cancer Institute. Name of the Reference Terminology. NCI Thesaurus. Code C117375.

The textual description of the terminology system that is being used. 